\title{
Pharmaceuticals and personal care products in the seawater around a typical subtropical tourist city of China and associated ecological risk
}

\author{
Hongzhe Chen ${ }^{1}$ (D) Wenfeng Chen ${ }^{1} \cdot$ Huige Guo ${ }^{1} \cdot$ Hui Lin ${ }^{1} \cdot$ Yuanbiao Zhang ${ }^{1}$ \\ Received: 29 September 2020 / Accepted: 30 December 2020 / Published online: 10 January 2021 \\ (C) The Author(s), under exclusive licence to Springer-Verlag GmbH, DE part of Springer Nature 2021
}

\begin{abstract}
Pharmaceuticals and personal care products (PPCPs) in the sea area surrounding a densely populated tourist city in southeastern China were investigated. In total, 32 PPCP pollutants classified into 23 categories were detected. Different spatial distribution patterns of PPCPs indicated possible contamination from runoff and multiple local sources. The labile-to-conservative ratios of PPCPs showed the influence of untreated domestic sewage. In addition, increased concentrations of ciprofloxacin, enrofloxacin, and erythromycin around aquaculture farms imply that aquaculture cannot be neglected as a source. The concentrations of oxytetracycline, ranitidine, ciprofloxacin, miconazole, and sulfamethizole were higher in the wet season than those in the dry season, and the difference in pharmaceutical consumption was suspected to be the main driving factor of this seasonal variation. The risk quotients calculated with the maximum concentrations of miconazole, triclosan, dehydronifedipine, and triclocarban exceeded 0.1, indicating potential moderate or high risks. Antibacterial agents in daily chemicals and azole broad-spectrum antifungals were associated with the highest risks in this study; this might be another significant pollution characteristic in the sea area around this subtropical tourist city.
\end{abstract}

Keywords PPCPs $\cdot$ Seasonal variance $\cdot$ Labile-to-conservative ratio $\cdot$ Characteristic pollutants $\cdot$ Risk quotients $\cdot$ Untreated domestic sewage $\cdot$ Aquaculture

\section{Introduction}

As emerging pollutants, pharmaceuticals and personal care products (PPCPs) leave various trace compounds in the

Responsible Editor: Ester Heath

Hongzhe Chen

chenhongzhe@tio.org.cn

Wenfeng Chen

chenwenfeng@tio.org.cn

Huige Guo

guohuige@tio.org.cn

Hui Lin

linhui@tio.org.cn

Yuanbiao Zhang

zhangyuanbiao@tio.org.cn

1 Ministry of Natural Resources of China, Third Institute of Oceanography, No. 178, Daxue Road, Siming District, Xiamen 361005, Fujian, China environment, including natural antibiotics, chemical synthetic antibacterial drugs, antibacterial agents from daily chemicals, psychotropic drugs and hormone drugs, chemicals from hair coloring, and even some inorganic and nonpolar organic substances (such as $\mathrm{TiO}_{2}$ and polyethylene microbeads from personal care products; Molins-Delgado et al. 2015). Generally, some common polar organic compounds, such as sulfonamides, antibacterial synergists, quinolones, $\beta$-lactam antibiotics, macrolide antibiotics, tetracycline antibiotics, and their metabolites or degradation products, are often identified in surveys of PPCPs in marine environments.

Designed to maintain/alter specific physiological functions, PPCPs can sometimes show biological activity against nontarget species and have been associated with potential environmental risks, and for the same reason, it is difficult for them to be completely degraded or metabolized by organisms in a short time (Godoy and Kummrow 2017). PPCPs are easily retained in the environment and even undergo a certain degree of bioaccumulation and biomagnification (Tang et al. 2020), resulting in "quasi persistence." It has been suggested (Cizmas et al. 2015) that in aquatic systems, some PPCPs 
might be associated with potential risks at environmentally relevant concentrations, and antibiotics may also promote the evolution of drug-resistant bacteria and drug-resistant genes. In addition, when different PPCPs are combined, the "cocktail effect" may occur in organisms, resulting in the enhancement or weakening of ecotoxicological effects (Godoy and Kummrow 2017). Several studies have also confirmed that residues of PPCPs in aquatic products affect human health (Lulijwa et al. 2020). Therefore, it is important to know which types of PPCPs are present and dominant in the environment.

Due to their relatively strong polarity and photolysis (Ali et al. 2017; Table S1), PPCPs persist in marine environments for a relatively short time. High dilution ratios in seawater also lead to rapid decreases in concentrations when PPCPs are discharged from sources. Therefore, the compositions of, abundance of and potential risks associated with PPCPs are suspected to be closely related to nearby sources. This has been confirmed by studies on PPCPs in lakes and coastal waters in recent years (Chen et al. 2020; Du et al. 2017; Wang et al. 2019; Zhang et al. 2018). Relatively short halflives in aquatic environments also mean that PPCP pollutants in the environment can be affected by their allowable upper limits in consumer goods (i.e., pharmaceuticals or personal care products) and the total consumption of consumer goods. For example, triclosan and triclocarban are widely used in personal care products in China (Sun et al. 2014b) without legal prohibition; in contrast, between 2014 and 2016, the European Union and the USA successively restricted and banned the use of triclosan and triclocarban in personal care products (European Commission 2014; United States Food and Drug Administration 2019). However, it is difficult to know whether such restrictions will have an indirect impact on the usage of triclosan and triclocarban in China, where similar products are used, and their presence in the environment. Characterization of PPCPs in marine environments may help to answer similar questions.

In a study on PPCPs in 37 river basins in Japan, Nakada et al. (2008) suggested that PPCP fluxes in rivers were significantly correlated with the population in each basin. Based on a similar assumption, the Chinese City of Xiamen was considered in this study. Xiamen is a typical subtropical coastal tourist city in southeastern China. With a population density of 2417 persons $/ \mathrm{km}^{2}$ (at the end of 2018; Huang 2019), it ranks in the top ten most densely populated cities among major cities in China. Additionally, due to the large number of tourists, Xiamen's annual tourism income accounted for $26.9 \%$ of the regional GDP in 2017; this was higher than that of Beijing, the most famous tourist city in China (Chen et al. 2019). A large population also drives the consumption of personal care products. Moreover, the concentration of medical resources in southern Fujian Province in Xiamen City (for example, there are 8.3 medical staff per one thousand citizens in Xiamen, which is much higher than that in surrounding areas, i.e., 5.3-6.0 medical staff per one thousand citizens; Huang 2019; Huang and Fang 2019; Li and Pan 2019; Zhangzhou Bureau of Statistics 2019) also leads to a high number of clinical patients and high pharmaceutical consumption here. Therefore, it can be inferred that among the sea areas along southeastern China, there might be a relatively high level of PPCP pollution in Xiamen Bay, the sea area surrounding Xiamen City.

The purpose of this study was to (1) investigate the presence of PPCP pollutants in Xiamen Bay; (2) analyze their spatial distributions and seasonal variance and explore their possible sources; and (3) assess their potential ecological risks.

\section{Material and methods}

\section{Sampling and preparation}

Xiamen Bay is located on the west coast of the Taiwan Strait, adjacent to Xiamen City of Fujian Province; due to jurisdictional issues, the study area did not include the coastal waters of Kinmen County (Fig. 1; Schlitzer 2018). According to differences in topographical and hydrological conditions, the study area was divided into smaller sea areas, such as Tong'an Bay, Haicang Bay, and the Jiulong Estuary. The three tributaries of the Jiulong River, with an average annual runoff of 14,126 million $\mathrm{m}^{3}$, flow into the Jiulong Estuary. The river basin consists of mostly hills, farmland, and rural residential areas. The surveys were conducted at 11 sites during August 2019 (sites X12 and X13 were not sampled) and 13 sites during January 2020 (Fig. 1), representing the wet season and dry season, respectively. The annual precipitation in Xiamen in 2019 was $1123 \mathrm{~mm}$ (China Meteorological Data Service Center 2020), which was lower than the perennial average value (1332.4 mm, 1981-2010) and much lower than $\sim 2000 \mathrm{~mm}$, which was recorded in 2016 (Chen et al. 2019). The precipitation amounts in August $2019(221.3 \mathrm{~mm})$ and January $2020(44.0 \mathrm{~mm})$ in this area were similar to the average values of previous years $(207.1 \mathrm{~mm}$ and $35.1 \mathrm{~mm}$ ); in the wet season, the Jiulong River runoff expands to the lower reaches, which it does not do in the dry season (Fig. S1).

The sampling, pretreatment, and HPLC/MS/MS analysis processes were modified from EPA Method 1694. This is one of the most widely used approaches for analyzing various PPCPs simultaneously (Zhang et al. 2020) and can be used to detect 74 main PPCPs and their metabolites/degradation products in seawater. The basic functions and some of their abbreviations are provided in Table S1. The optimized chromatographic properties, mass spectrometric properties, method detection limits (MDLs), and method minimum levels of quantitation (MLs) of these PPCPs are provided in Tables S2-S4. In brief, at each site, surface water was collected and transferred into two 2-L glass flasks with stoppers. Samples were 
Fig. 1 Locations of the sampling sites and some wastewater treatment plants (WWTPs) in Xiamen City. Sampling sites are marked with red stars, and WWTPs are marked with black triangles. Sites X12 and X13 were not included in the survey during the wet season. Site X13 was in the Jiulong Estuary
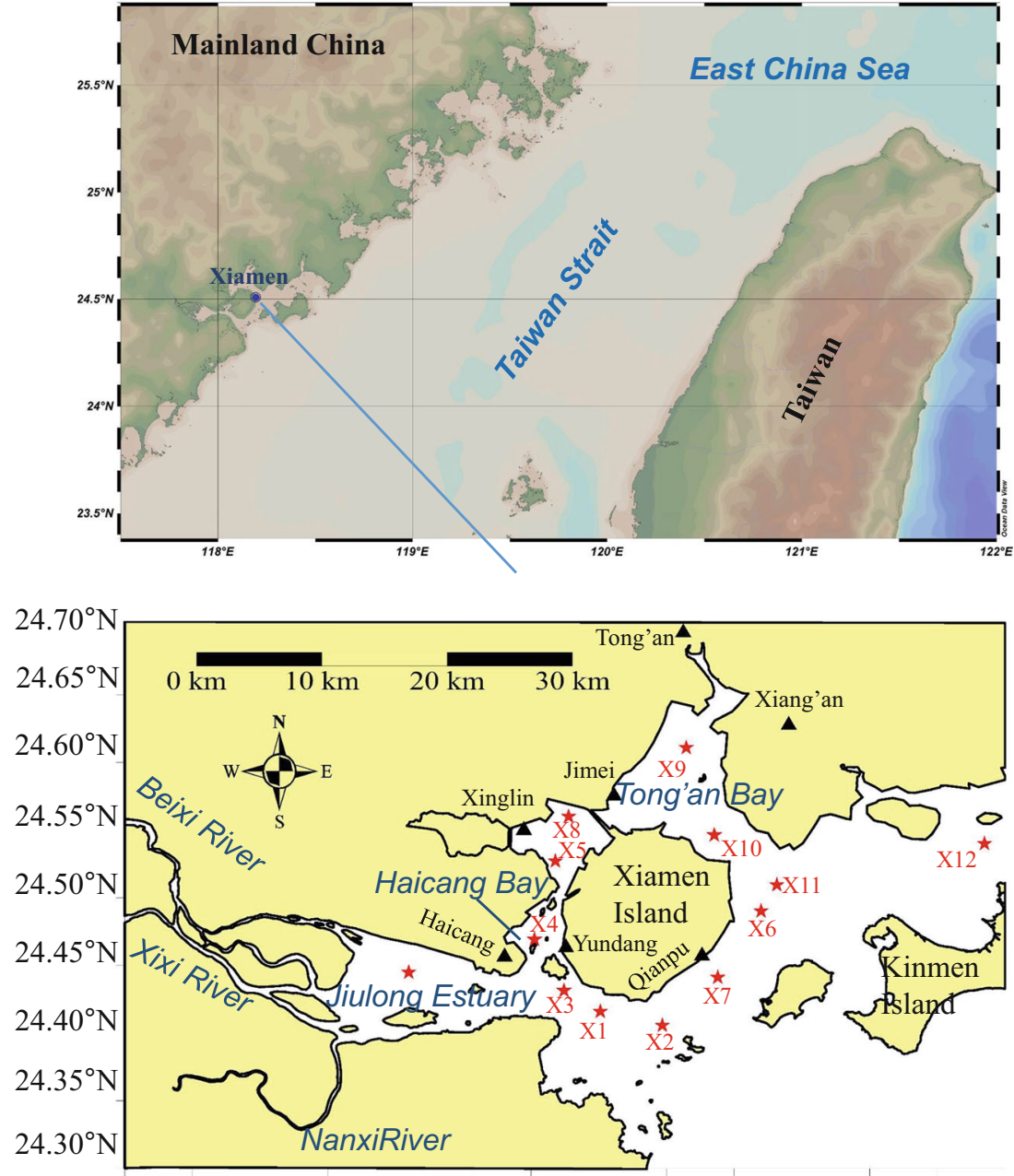

maintained in the dark and refrigerated. Generally, pretreatment was completed within $24 \mathrm{~h}$; the samples that were not processed in time were filtered and then transferred to polyethylene bottles for freezing. The thawed samples were pretreated within $24 \mathrm{~h}$ after thawing. The pretreatment, HPLC/MS/MS analysis, quality assurance, and quality control processes are provided in Sections 1 and 2 of the Supporting Material. The salinity (practical salinity scale; Fig. S1) of seawater was determined by a SonTek CastAway®-CTD instrument.

\section{Statistical analysis}

Cluster analysis was used to distinguish the spatial distribution characteristics of PPCP pollutants. Ward's method was performed in the cluster analysis, with the squared Euclidean distance as a measure of similarity. Based on the groups identified by the cluster analysis, ANOVA was performed to determine whether the differences in PPCP concentrations between groups were significant. When significant differences were detected (at $\alpha=0.05$ ) and the group number was $>2$, a post hoc Scheffe test was carried out to perform pairwise comparisons between group means, since the sample sizes of the groups were unequal. Before ANOVA, the Shapiro-Wilk normality test and Levene test for homogeneity of variance were carried out using untransformed or transformed data (Table S5). For data with inhomogeneous variance or an abnormal distribution ( $p \leq 0.05$ ), Mann-Whitney $U$ test (two groups) or Kruskal-Wallis test (more than two groups) was performed instead. Cluster analyses, one-way ANOVA, MannWhitney $U$ tests, and Kruskal-Wallis tests were conducted with SPSS. Similarity percentages (SIMPER) analysis was also performed to identify the most important distinguishing PPCPs between groups. The SIMPER analysis was carried out using PAST 3.20 (Hammer et al. 2001) based on the Bray-Curtis similarity index. The least squares method was used to analyze linear regression between salinity and the concentrations of PPCPs via Microsoft Excel.

\section{Ecological risk assessment}

In view of the variety of PPCPs and limited toxicological data, risk quotients (RQs) were used for PPCPs to conduct a 
screening-level ecological risk assessment. Generally (Lützhøft et al. 2014; Mohtar et al. 2019), RQ = PEC/PNEC, where PEC is the predicted environmental concentration (measured environmental concentration was used here) and PNEC is the predicted no-effect concentration. When RQ $>1$, harmful ecological effects cannot be excluded; when $\mathrm{RQ}=1$, pollutants alone are unlikely to cause ecological risks, and when $\mathrm{RQ}<1$, pollutants are unlikely to cause harmful ecological effects. However, Lemly (1996) suggested that the RQs (expressed as hazard quotients) should be qualitatively discussed at a broader level; similarly, Xu et al. (2013) and Guruge et al. (2019) suggested that the RQs of antibiotics and PPCPs could be classified into four categories: high risk $(\mathrm{RQ}>1)$, moderate risk $(0.1<\mathrm{RQ}<1)$, low risk $(0.01<R Q<0.1)$, and safe $(R Q<0.01)$; this classification scheme was applied in this study. According to the EU's Technical Guidance (European Commission-Joint Research Centre et al. 2003), the equation $\mathrm{PNEC}=\mathrm{TDD} / \mathrm{AF}$ should be applied, where TDD is the toxicological dose descriptor, which usually refers to the values of toxicological test end points (such as EC50, LC50, and NOEC), and AF is the assessment factor, with the values provided by Technical Guidance (European Commission-Joint Research Centre et al. 2003). Following this guideline, the aquatic organism-related criteria for seawater (salinity $>5$ ) are mainly applicable to seawater communities that need to be protected, but the toxicity data obtained from freshwater organisms should not be rejected. TDD values were obtained from the KAshinhou Tool for Ecotoxicity (KATE) 2020 version 1.0 (KATE 2020). Values were calculated considering quantitative structure-activity relationships based on a large number of acute and chronic toxicological data (including EC50, LC50, and NOEC values) from various model organisms, such as fish, Daphnia, and algae (Furuhama et al. 2010). Due to the lack of toxicological data on the effects of PPCPs on sensitive organisms in marine ecosystems, data from freshwater aquatic organisms and marine organisms are applied indiscriminately here. The n-octanol-water partition coefficients, $K_{\mathrm{OW}}$, used in the calculation were obtained from KOWWIN v1.68 (September 2010) of the Estimation Programs Interface, USEPA; the experimental data in the database were used when possible, and simulated values were applied when necessary. Since the KATE 2020 did not provide any TDD values for ranitidine, the PNEC for ranitidine was calculated with the data obtained from Isidori et al. (2009).

\section{Results and discussion}

\section{Presence}

In the study area, 32 of 72 PPCP compounds were detected at a minimum of one site. Thirteen compounds, including carbadox, carbamazepine, thiabendazole, diphenhydramine, cotinine, erythromycin dehydrate, oxolinic acid, erythromycin, oxytetracycline (OTC), naproxen, gemfibrozil, triclocarban, and cimetidine, were detected in all samples, and another 13 compounds were detected in more than $50 \%$ of the samples (Table 1). The maximum concentration of detected PPCPs was $84 \mathrm{ng} \mathrm{L}^{-1}$ (naproxen).

In view of the great differences in the MDLs and detection frequencies reported, the maximum and/or median concentrations of several PPCPs were compared with data previously reported in China (Table S6). In the study area, the concentrations of PPCPs, except for naproxen and enrofloxacin, in seawater were similar to or lower than the maximum levels in the Jiulong Estuary and its downstream area reported by Sun et al. (2016). This might be related to the increased consumption of these two pharmaceutical ingredients in recent years. For example, naproxen accounted for $<2 \%$ of total nonsteroidal anti-inflammatory drug (NSAID) sales in China in 2011 (the median among 15 economies was 9.4\%; McGettigan and Henry 2013). As a low-risk NSAID, naproxen was supposed to be one substitute for high-risk NSAIDs (McGettigan and Henry 2013). However, the maximum concentration of naproxen in seawater obtained in this study $\left(84.3 \mathrm{ng} \mathrm{L}^{-1}\right)$ did not exceed those reported from the Yellow Sea and East China Sea (271.3 ng L ${ }^{-1}$; Chen et al. 2020); the maximum/ median concentrations of enrofloxacin were much lower than those in samples obtained in the Bohai Sea and Yellow Sea adjacent to mariculture farms (Du et al. 2019; Han et al. 2020).

\section{Spatial distributions}

The relative abundance distributions of 32 detected compounds are shown in Fig. 2. Cluster analysis was performed to compare differences among sites. Here, relative concentration refers to the ratio of the investigated concentration to the median concentration for each PPCP in the total 24 samplings during the two surveys. In the wet season, all the sampling sites except site $\mathrm{X} 1$ were divided into two groups (group south, including sites $\mathrm{X} 2, \mathrm{X} 3, \mathrm{X} 4, \mathrm{X} 6$, and $\mathrm{X} 7$; group north, including sites $\mathrm{X} 5, \mathrm{X} 8, \mathrm{X} 9, \mathrm{X} 10$, and $\mathrm{X} 11$ ), with a distance $<$ 5 (Fig. 3). The detection frequencies of these 32 PPCPs for sites in each group were listed in Table S7. The sites in the two groups were almost equally affected by river fresh water (Fig. S1). As discussed in the 2012-2014 surveys of the Jiulong River and its lower reaches by Lv et al. (2014) and Sun et al. (2016), the Jiulong River is likely an important input source of several PPCPs, especially NSAIDs. However, the larger amount of fresh water in the wet season also seemed to reduce the difference between the two groups. Additional freshwater diluted the PPCPs in the Jiulong River and transported them a long distance. Specifically, the concentrations of five PPCPs (warfarin, acetaminophen, gemfibrozil, carbamazepine, and thiabendazole) showed negative linear correlations (Pearson's linear correlation coefficient $r>0.602$ for the samples, $n=11, p<0.05$ ) with the salinity of the whole sea area; 


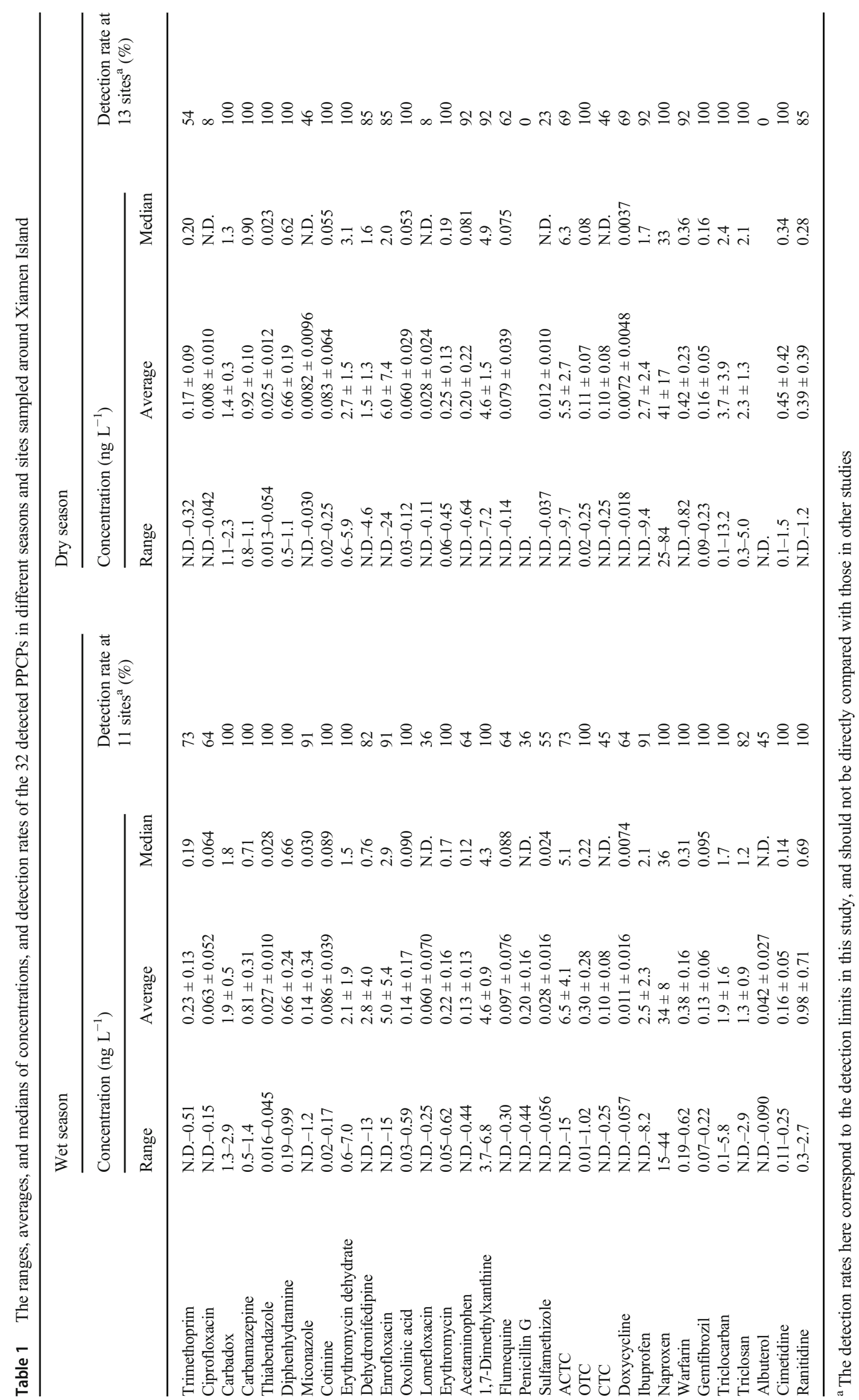


Fig. 2 The relative abundance distribution of different PPCPs at each site. Relative concentration refers to the ratio of the investigated concentration to the median concentration for each PPCP in the total 24 samplings during the two surveys: a wet season and $\mathbf{b}$ dry season
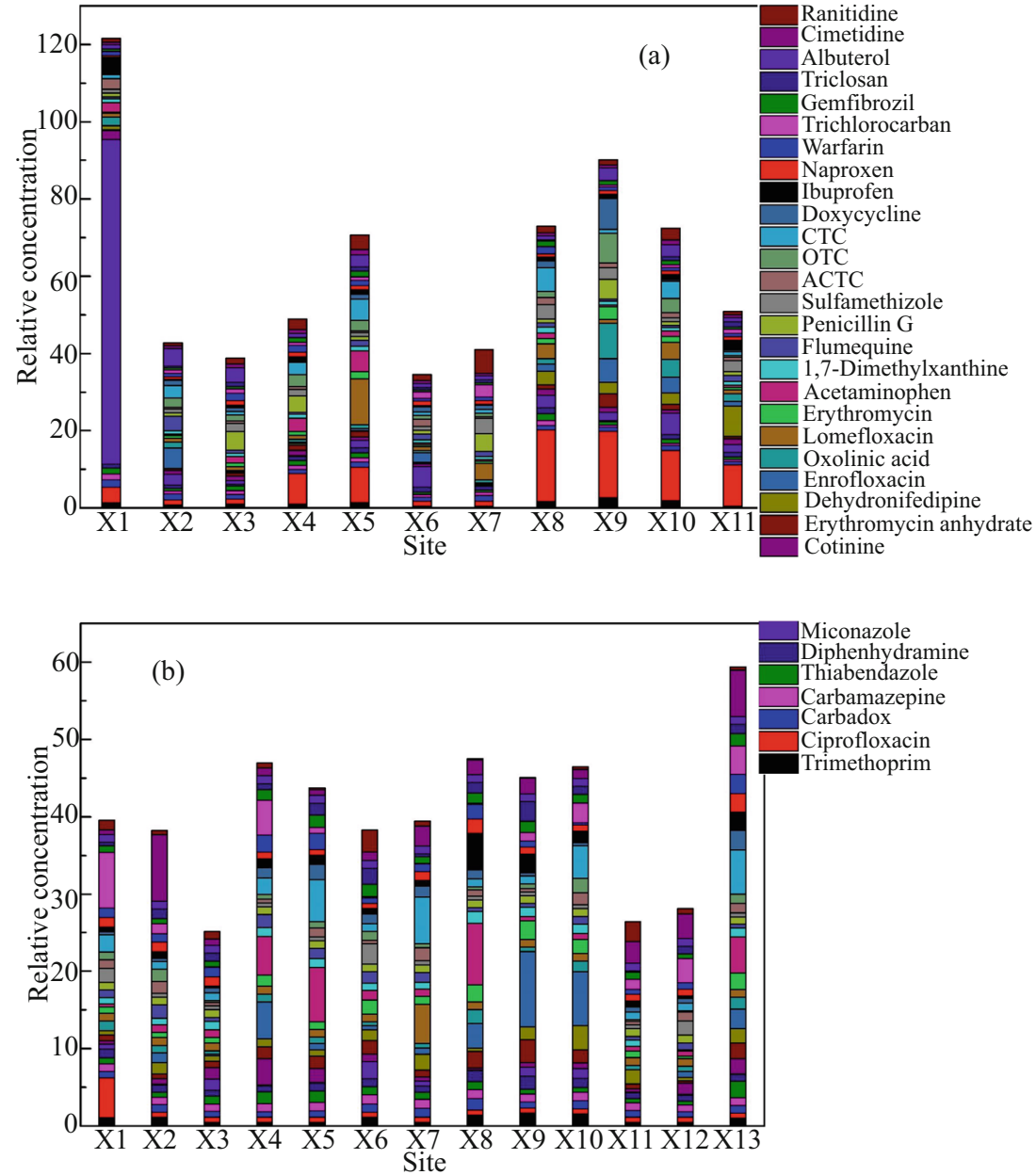

their main sources were suspected to be the upper reaches of the Jiulong River. Notably, out of these five compounds, only acetaminophen is a NSAID.

Based on ANOVA and the Mann-Whitney $U$ test, five PPCPs (trimethoprim, ciprofloxacin, dehydronifedipine, ibuprofen, and oxolinic acid; Table S8) were believed to have contributed to the difference between the two groups in the wet season. It is suggested by the SIMPER analysis that the mean concentrations of these five PPCPs were higher in group north than in group south. Ciprofloxacin, dehydronifedipine, and oxolinic acid were the top three contributors to the dissimilarity. This suggests that these five pollutants were characteristic pollutants of group north in the wet season. Considering that these five PPCPs did not coincide with the five PPCPs attributable to input from the Jiulong River sources, it can be suggested that they represent the contribution of local sources from Haicang Bay to Tong'an Bay.

The difference in abundance at site X1 might be due to a large amount of land-based emissions in the vicinity of this sample site. According to the SIMPER analysis (Table S9) and the relative concentrations of PPCPs (Fig. 2), miconazole was the most characteristic PPCP pollutant at this site, contributing to $71.09 \%$ of the difference with that of group south and $62.27 \%$ of the difference with that of group north. Miconazole had the highest $K_{\mathrm{OW}}$ of the substances considered in this study, which might explain why other peripheral sites were not affected by this pollutant. A high $K_{\mathrm{Ow}}$ value means that a PPCP easily absorbed or adsorbed by organisms or organic matter, reducing transportation in seawater in the short term.

In the dry season, the distance between groups seemed to be longer than that in the wet season (Fig. 3). The 13 sites were divided into three groups (group Xiamen, including sites X1, $\mathrm{X} 2, \mathrm{X} 3, \mathrm{X} 6, \mathrm{X} 7, \mathrm{X} 11$, and X12; group Jiulong, including sites $\mathrm{X} 4, \mathrm{X} 5, \mathrm{X} 8$, and $\mathrm{X} 13$; and group Tong'an, including sites $\mathrm{X} 9$ and X10) with a distance of 15 . Twelve PPCPs (thiabendazole; erythromycin anhydrate; erythromycin; enrofloxacin; diphenhydramine; 1,7-dimethylxanthine; doxycycline; warfarin; gemfibrozil; acetaminophen; ibuprofen; and ranitidine; Table S8) were suspected to contribute to the differences among the three groups in the dry season, but only ten of these compounds showed significant differences in the post hoc test (Table 2). For enrofloxacin, diphenhydramine, erythromycin anhydrate, and erythromycin, the highest mean concentrations 

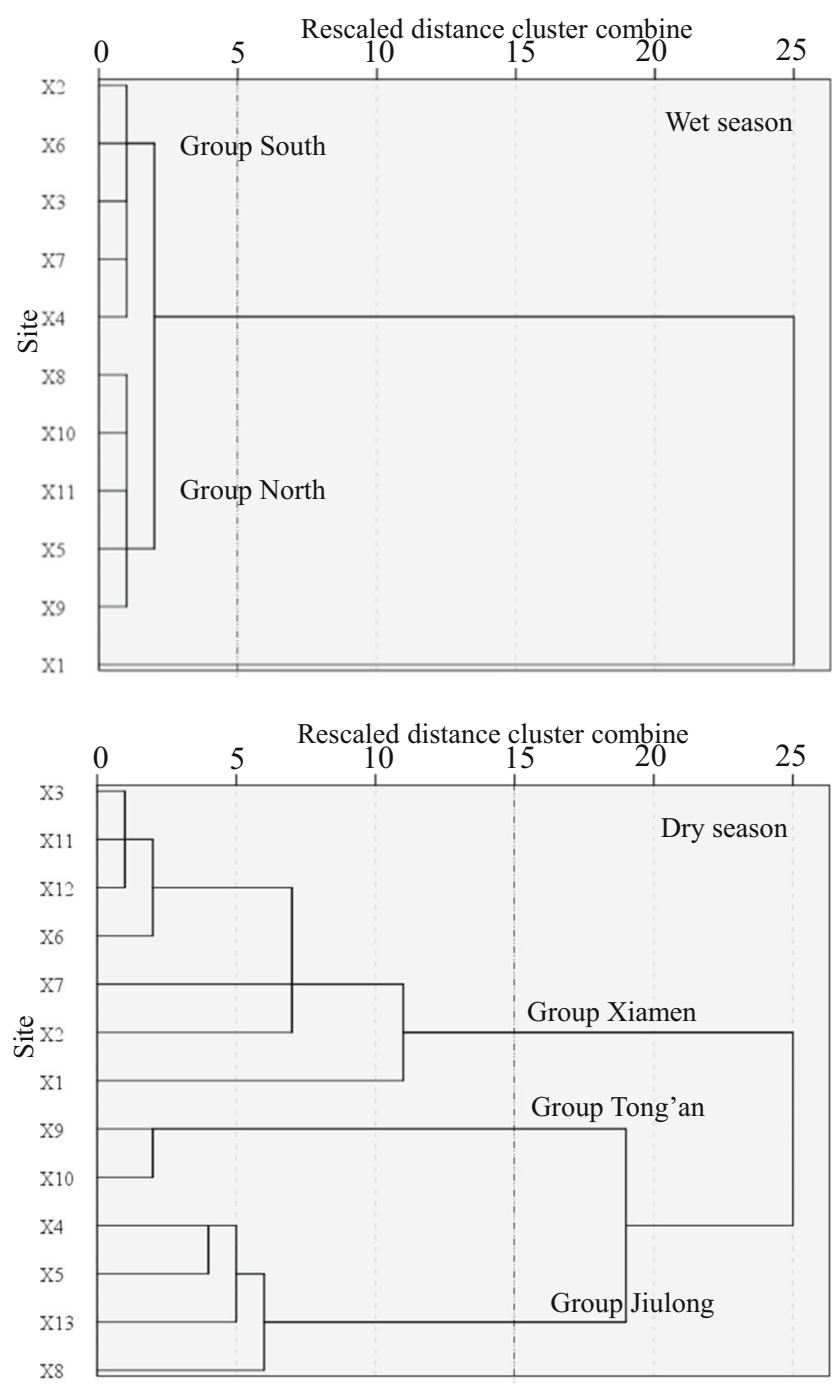

Fig. 3 Dendrograms for cluster analyses of different sites based on relative PPCP abundance

occurred in Tong'an Bay; the concentrations were slightly higher than the mean concentrations in group Jiulong (sites in the Jiulong Estuary and Haicang Bay, which were obviously affected by diluted current from the Jiulong River in the dry season; Fig. S1), but they were significantly higher than those in the sea areas adjacent to sites in group Xiamen. This difference may be due to the semiclosed terrain of Tong'an Bay. In the dry season, when the input of fresh water is low, the terrain might prevent pollutants from local sources from diffusing. A large number of residents live around Tong'an Bay, especially in Gaoqi (Fig. 1). In recent years, this sea area has suffered from the lack of domestic sewage treatment capacity (Table S10). The issue concerning sewage discharged into the sea in Xiamen City has been publicly criticized by China's central inspection team for ecological and environmental protection (Ministry of Ecology and Environment of the People's Republic of China 2020). In addition, there are some mariculture farms in or around Tong'an Bay (Chen et al. 2019), including some indoor farms that were identified in field surveys. Ciprofloxacin in the wet season and enrofloxacin in the dry season were the most important characteristic PPCPs in this sea area, both of which are third-generation quinolones. Together with erythromycin, they are among the most commonly used veterinary antibiotics in aquaculture in China and have been widely detected in the receiving waters near aquaculture farms (Chen et al. 2015; Han et al. 2020; He et al. 2016; Mo et al. 2017). For thiabendazole, acetaminophen, doxycycline, and warfarin, the Jiulong River was the main source (Table 2). Strong linear correlations with salinity $(r>0.78)$ were shown, supporting this statement. In addition to these compounds, four other compounds (gemfibrozil; 1,7-dimethylxanthine; cotinine; and naproxen) were also linearly correlated with salinity $(r>$ 0.553 for $n=13$ and $p<0.05$ ) in the dry season. For ibuprofen and gemfibrozil, the Jiulong River might be a main source due to higher mean concentrations (Table 2), but there were no significant differences between the concentrations in groups Tong' an and Jiulong, suggesting that there might be a secondary source of these two compounds nearby. According to the SIMPER analysis (Table S9), among the 12 compounds showing significant intergroup differences (Table 2), enrofloxacin, acetaminophen, and warfarin contributed to the difference between groups Jiulong and Tong'an; the key distinguishing compounds between groups Jiulong and Xiamen were acetaminophen, enrofloxacin, and ibuprofen. The top three contributing compounds between groups Tong'an and Xiamen were enrofloxacin, erythromycin anhydrate, and ibuprofen.

To further understand the possible sources of PPCPs, the labile-to-conservative ratios of PPCPs (Sun et al. 2016) were also provided (Fig. 4). Common treatment processes (e.g., A2/ O; Ashfaq et al. 2017) in wastewater treatment plants (WWTPs) have high removal efficiency for some (labile) PPCPs (ibuprofen, with an $~ 90 \%$ removal rate and acetaminophen, with an $\sim 100 \%$ removal rate), while they have low removal efficacy for and even enrich other (conservative) PPCPs (e.g., < $0 \%$ removal rate for ciprofloxacin). Even advanced treatment technologies, such as membrane bioreactors, cannot remove some conservative PPCPs effectively $(<20 \%$ for carbamazepine; Prasertkulsak et al. 2019). Čelić et al. (2019) pointed out that conservative PPCPs such as trimethoprim and carbamazepine could be chemical markers of WWTP discharge in seawater.

Therefore, a high labile-to-conservative ratio might imply the impact of raw sewage without treatment from WWTPs. According to the PPCP removal ratios in several WWTPs in Xiamen provided by Sun et al. (2014a) and Ashfaq et al. (2017), acetaminophen, ibuprofen, gemfibrozil, and naproxen were viewed as labile PPCPs in this study, with removal rates $>70 \%$, while carbamazepine, triclocarban, triclosan, 
Table 2 The results of post hoc test calculated with the data in dry season, and possible main sources for these PPCPs

\begin{tabular}{|c|c|c|c|c|c|c|}
\hline Dependent variable & (I) group & (J) group & Mean difference (I-J) & Std. error & Sig. & Possible main sources \\
\hline \multirow[t]{3}{*}{ Enrofloxacin } & Jiulong & Xiamen & $0.383 *$ & 0.100 & 0.011 & \multirow{12}{*}{$\begin{array}{l}\text { Local sources around Tong'an Bay } \\
\text { (primary) and Jiulong River (secondary) }\end{array}$} \\
\hline & Jiulong & Tong'an & $-0.420 *$ & 0.138 & 0.037 & \\
\hline & Xiamen & Tong'an & $-0.803 *$ & 0.127 & 0.000 & \\
\hline \multirow[t]{3}{*}{ Diphenhydramine } & Jiulong & Xiamen & 0.135 & 0.151 & 0.679 & \\
\hline & Jiulong & Tong'an & -0.423 & 0.209 & 0.179 & \\
\hline & Xiamen & Tong'an & $-0.558 *$ & 0.193 & 0.048 & \\
\hline \multirow[t]{3}{*}{ Erythromycin anhydrate } & Jiulong & Xiamen & $1.012 *$ & 0.301 & 0.023 & \\
\hline & Jiulong & Tong'an & -0.497 & 0.416 & 0.513 & \\
\hline & Xiamen & Tong'an & $-1.509 *$ & 0.385 & 0.010 & \\
\hline \multirow[t]{3}{*}{ Erythromycin } & Jiulong & Xiamen & 0.798 & 0.314 & 0.083 & \\
\hline & Jiulong & Tong'an & -0.414 & 0.434 & 0.646 & \\
\hline & Xiamen & Tong'an & $-1.212 *$ & 0.401 & 0.039 & \\
\hline \multirow[t]{3}{*}{ Ibuprofen } & Jiulong & Xiamen & $1.760 *$ & 0.602 & 0.046 & \multirow{6}{*}{$\begin{array}{l}\text { Jiulong River (main) and local sources } \\
\text { around Haicang or Tong'an (possible) }\end{array}$} \\
\hline & Jiulong & Tong'an & 0.413 & 0.832 & 0.885 & \\
\hline & Xiamen & Tong'an & -1.347 & 0.771 & 0.264 & \\
\hline \multirow[t]{3}{*}{ Gemfibrozil } & Jiulong & Xiamen & $0.123 *$ & 0.036 & 0.020 & \\
\hline & Jiulong & Tong'an & 0.037 & 0.049 & 0.763 & \\
\hline & Xiamen & Tong'an & -0.087 & 0.046 & 0.215 & \\
\hline \multirow[t]{3}{*}{ Thiabendazole } & Jiulong & Xiamen & $0.764 *$ & 0.192 & 0.009 & \multirow[t]{12}{*}{ Jiulong River } \\
\hline & Jiulong & Tong'an & $0.929 *$ & 0.265 & 0.018 & \\
\hline & Xiamen & Tong'an & 0.165 & 0.246 & 0.803 & \\
\hline \multirow[t]{3}{*}{ Acetaminophen } & Jiulong & Xiamen & $5.346^{*}$ & 0.558 & 0.000 & \\
\hline & Jiulong & Tong'an & $5.483 *$ & 0.771 & 0.000 & \\
\hline & Xiamen & Tong'an & 0.137 & 0.713 & 0.982 & \\
\hline \multirow[t]{3}{*}{ Doxycycline } & Jiulong & Xiamen & $0.192 *$ & 0.058 & 0.025 & \\
\hline & Jiulong & Tong'an & $0.287 *$ & 0.080 & 0.016 & \\
\hline & Xiamen & Tong'an & 0.095 & 0.074 & 0.466 & \\
\hline \multirow[t]{3}{*}{ Warfarin } & Jiulong & Xiamen & $1.200 *$ & 0.164 & 0.000 & \\
\hline & Jiulong & Tong'an & $1.651^{*}$ & 0.227 & 0.000 & \\
\hline & Xiamen & Tong'an & 0.450 & 0.210 & 0.150 & \\
\hline \multirow[t]{3}{*}{ 1,7-Dimethylxanthine } & Jiulong & Xiamen & 0.452 & 0.169 & 0.067 & \multirow[t]{6}{*}{ Unclear } \\
\hline & Jiulong & Tong'an & 0.035 & 0.233 & 0.989 & \\
\hline & Xiamen & Tong'an & -0.417 & 0.216 & 0.205 & \\
\hline \multirow[t]{3}{*}{ Ranitidine } & Jiulong & Xiamen & -0.980 & 0.476 & 0.171 & \\
\hline & Jiulong & Tong'an & 0.168 & 0.658 & 0.968 & \\
\hline & Xiamen & Tong'an & 1.148 & 0.609 & 0.218 & \\
\hline
\end{tabular}

*The mean difference is significant at the 0.05 level

ciprofloxacin, and thiabendazole were regarded as representative conservative PPCPs, with removal ratios $<0 \%$. Considering the median concentrations and detection frequencies (Table 1) and predicted half-lives in water of the studied PPCPs (Table S1), ibuprofen, gemfibrozil, carbamazepine, triclocarban, and triclosan were chosen to calculate the labile-to-conservative ratio of PPCPs. The ratios were calculated by the following equation, labile-to-conservative ratio $=$ $\left(C_{\text {ibuprofen }}+C_{\text {gemfibrozil }}\right) /\left(C_{\text {carbamazepine }}+C_{\text {triclocarban }}+\right.$ $C_{\text {triclosan }}$ ), where $C$ was the average concentration of corresponding PPCP. The results presented in Fig. 4 show that there were untreated land-based discharges at site $\mathrm{X} 1$ in the wet season. The highest labile-to-conservative ratios appeared in Tong'an Bay (sites X8, X9, and X10), Haicang Bay (site X4), and the Qianpu coast (site X11; Fig. 1), revealing deficiencies in sewage treatment capacity in adjacent urban areas. It is reasonable to believe that the planning and construction of domestic sewage treatment plants reflect current deficiencies in sewage treatment capacity; in fact, the sites with the highest labile-to-conservative ratios were close to WWTP sites in 


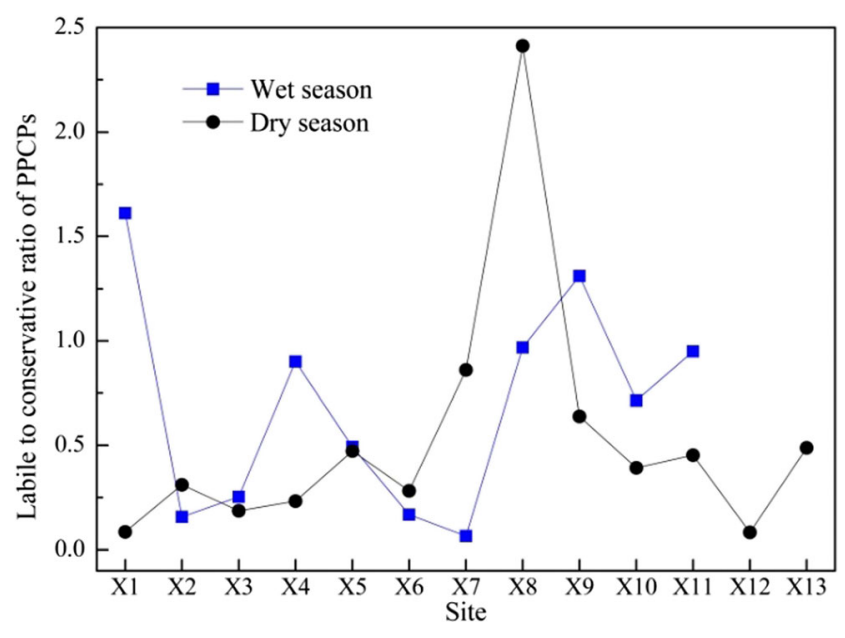

Fig. 4 The ratio of labile-to-conservative PPCPs at each site

planning, construction, and expansion stages (Fig. 4 and Table S10). Therefore, untreated domestic sewage could be an important source of PPCPs in seawater in these areas. On the other hand, the labile-to-conservative ratio in the Jiulong Estuary (site X13) in the dry season was not as high as expected, probably due to new sewage treatment facilities upstream. In addition, the labile/conservative PPCPs selected might also affect the results. The main sources of the five selected PPCPs are sewage, but the main potential sources around the estuary were pond culture operations that were far from large-scale domestic sewage sources. This might have a great influence on the concentrations of labile PPCPs.

\section{Seasonal variations in PPCP concentrations}

Excluding site X1 (with abnormal data in the wet season) and sites X12 and X13 (surveyed only in the dry season), the relative concentrations of PPCPs at the sites were analyzed to compare differences between the two seasons. There were significant differences in the relative concentrations of six compounds, namely OTC, ranitidine, ciprofloxacin, miconazole, sulfamethizole, and cimetidine (Table S8). The mean concentrations of the first five PPCPs were higher in the wet season than in the dry season, and ciprofloxacin contributed the most (15.67\%) to the dissimilarity according to the SIMPER analysis (Table S9). As discussed in "Spatial distributions," there were little correlations between the spatial distributions of these six PPCPs and salinity in both the wet season and dry seasons; in fact, in the dry season, the mean concentrations in group Jiulong were equal to or even lower than those in group Xiamen. Therefore, the main contamination pathways in this sea area might not be runoff from the Jiulong River.

Seasonal variations in PPCP concentrations in surface water are affected by many factors. Several environmental factors (such as the dilution effect in the flood season; Ding et al. 2017; Kim et al. 2016) and socioeconomic factors (such as the high consumption of pharmaceuticals in the flu/cold season, Guibal et al. 2018; Zhang et al. 2019) have often been included in discussions. At the sampling sites that were long distances from sources, photodegradation led to a lower concentration of sulfamethoxazole in the dry season than that in the wet season (Archundia et al. 2018). However, considering the much closer distances from potential sources in this study, changes in pharmaceutical consumption might be a direct cause of the significant seasonal variance. Assress et al. (2020) found a higher level of miconazole in wastewater in summer than in winter. Peng et al. (2012) suggested that the climate in the dry season was not suitable for the growth and propagation of fungi, which might lead to less use and discharge of the antifungal pharmaceuticals (e.g., miconazole). Similar explanations can be applied to pharmaceuticals other than ciprofloxacin, which is often used as a veterinary antibiotic in aquaculture. OTC and ranitidine are commonly used for gastrointestinal diseases, and sulfamethizole is used for the treatment of urinary tract infection. None of these compounds are consumed as main pharmaceuticals in the flu season; they are more likely to be consumed in the summer (wet season).

Interestingly, both ranitidine and cimetidine are $\mathrm{H} 2$ receptor antagonists. However, the concentration of cimetidine reported in the 2020 survey (dry season) increased significantly. Ranitidine was considered a substitute for cimetidine (Walker 2011) since the efficacy of ranitidine in inhibiting gastric acid secretion is greater than that of cimetidine (McCarthy 1983), and there was no evidence of serious side effects before 2019. Although cimetidine has more clinical applications than ranitidine, including the treatment of peptic ulcers (Bourinbaiar and Jirathitikal 2003; Lefranc et al. 2006), the different temporary trends between these two pharmaceuticals cannot be explained. In the summer of 2019, independent laboratory testing found the human carcinogen $\mathrm{N}$-nitrosodimethylamine in ranitidine. The USFDA (United States Food and Drug Administration 2020) warned the public in September 2019 and established the requirement for the removal of all ranitidine products by April 2020. Although there has been no clear ban on or recall requirements for ranitidine in China, these messages might still affect doctors' decisions about prescribing clinical pharmaceuticals. In fact, there was no significant difference in the total concentrations of these two H2-receptor antagonists between the two seasons (Table S8).

\section{Potential ecological risk ranking}

The potential ecological risk rankings of PPCPs in this area are listed in Table S11. Though the rankings varied according to different statistics (mean, median and maximum), triclosan, miconazole, and dehydronifedipine were always the top three 
compounds with the highest RQs. Other PPCPs with high rankings (in the top ten) calculated with maximum concentrations include triclocarban, naproxen, ranitidine, erythromycin anhydrate, ibuprofen, diphenhydramine, and carbamazepine. The RQ of miconazole calculated with the maximum concentration was greater than 1 , indicating high risk. The RQs of dehydronifedipine, triclosan, and triclocarban calculated with the maximum concentrations were greater than 0.1 , indicating moderate risk. From the perspective of controlling ecological risk, the monitoring of these compounds should be considered a priority.

The situation of cimetidine and ranitidine mentioned in "Seasonal variations in PPCP concentrations" reveals that levels of pharmaceutical agent categories can reflect long-term trends better than those of specific pharmaceuticals. Therefore, it is meaningful to assess ecological risks based on pharmaceutical categories. The RQ values of the PPCP categories and their rankings are provided in Table S12. Here, it is assumed that the harmful effects of PPCPs on sensitive species are similar within the same PPCP category, and the RQ values of each category were directly influenced by the PPCPs belonging to this category. Although various PPCPs belonging to quinolones and tetracycline antibiotics were detected in this sea area, their RQ values were lower than $10^{-3}$. The RQs for antibacterial agents in daily chemicals (triclosan and triclocarban) and azole broad-spectrum antifungal agents (miconazole) were the highest. Generally, the ecological risks associated with the top three PPCP categories (antibacterial agents in daily chemicals, azole broad-spectrum antifungal agents, and dihydropyridine calcium antagonists) were low or moderate, while the risks associated with the other categories were considered safe in the study area. However, it should be noted that this result does not accurately and fully measure the ecological risk of any specific PPCP category. Similar PPCPs that cannot be detected by the USEPA method 1694-2007 have been widely used since 2007. Taking histamine H2-receptor antagonists as an example, roxatidine, lafutidine, and famotidine account for high proportions in this category in terms of sales in China. However, their risks were not assessed in this study. Moreover, proton pump inhibitors, with the same clinical use as histamine H2-receptor antagonists, occupy a large amount of the market share.

\section{Conclusions}

Here, 32 PPCP compounds in 23 categories were screened. The study locations were divided into two groups in the wet season: one in the northwest zone of the study area, where local sources and diluted water from the Jiulong River served as main sources, and the other in the southeast zone, representing the other part of the study area with relatively favorable geographical conditions for pollutant diffusion in seawater. In contrast, due to hydrological and topographical factors, three groups were classified in the dry season. Local sources in Tong'an Bay and discharges along the Jiulong River were viewed as the main sources in two of these three groups (groups Tong'an and Jiulong). Different groups had their own characteristic PPCP pollutants. Additionally, based on the labile-to-conservative ratios of PPCPs, the distributions of PPCPs seemed to delineate the areas affected by untreated domestic sewage discharge. This reveals deficiencies in sewage treatment capacity. Finally, the significant concentrations of widely used veterinary antibiotics (i.e., enrofloxacin, ciprofloxacin, and erythromycin) implied that aquaculture farms were nonnegligible sources in the study area, which might also be a common feature around coastal tourist cities in China.

Among the 32 PPCPs detected, the RQs of the top four compounds calculated with the maximum concentrations, i.e., miconazole, triclosan, dehydronifedipine, and triclocarban, were greater than 0.1 , indicating moderate or high potential ecological risks. Although the ecological risks of all the major PPCPs in each category were not enumerated, the RQ values of the 23 investigated PPCP categories were ranked. The RQ values calculated with the mean concentrations of the investigated antibacterial agents in daily chemicals (triclosan and triclocarban) and azole broad-spectrum antifungal agents (miconazole) were the highest, at greater than 0.1 , indicating moderate risks. Significant seasonal differences in the concentrations of azoles between the two seasons and increased concentrations in the wet season indicated that azoles should be a focus, especially in the hot and humid seasons; conversely, high detection frequencies of antibacterial agents in daily chemicals in both seasons indicate that they should remain a focus throughout the year.

In this study, runoff from the Jiulong Estuary influenced the spatial distribution of PPCPs in the different seasons. However, the seasonal variation in PPCP mean concentrations was not significantly affected by natural factors such as the transport/dilution effect of runoff; instead, some socioeconomic factors, such as local policies, technology, and consumption levels, might have had a great impact on compound concentrations in sea areas surrounding this coastal city. In general, the characteristics and concentrations of PPCPs in seawater were significantly affected by pharmaceutical consumption. With the advancement of modern medical science, new pharmaceuticals will continue to be developed for clinical use. During the COVID-19 pandemic, the WHO identified promising existing drugs for coronavirus treatment, such as remdesivir, ritonavir/lopinavir, interferon- $\beta$, chloroquine, and hydroxychloroquine (Kupferschmidt and Cohen 2020). It can be supposed that emerging sources of micropollutants might be generated. The continuous updating of the priority PPCP control list will positively influence ecological security.

Supplementary Information The online version contains supplementary material available at https://doi.org/10.1007/s11356-020-12335-1. 
Acknowledgments Thanks are given to KATE for providing the QSAR model.

Authors' contributions $\mathrm{HC}$ designed the study, analyzed the data, and wrote the paper. WC and $\mathrm{HG}$ were major contributors in performing the research. $\mathrm{HL}$ and $\mathrm{YZ}$ were major contributors in writing the manuscript. All authors read and approved the final manuscript.

Funding The study was supported by Fujian Provincial Natural Science Foundation of China (Grant No. 2016J05102) and China Blue Bay Remediation Action Plan.

Data availability The datasets used and/or analyzed during the current study are available from the corresponding author on reasonable request.

\section{Compliance with ethical standards}

Competing interests The authors declare that they have no competing interests.

\section{References}

Ali AMM, Kallenborn R, Sydnes LK, Rønning HT, Alarif WM, AlLihaibi S (2017) Photolysis of pharmaceuticals and personal care products in the marine environment under simulated sunlight conditions: irradiation and identification. Environ Sci Pollut Res 24: 14657-14668. https://doi.org/10.1007/s11356-017-8930-8

Archundia D, Boithias L, Duwig C, Morel M-C, Aviles GF, Martins JMF (2018) Environmental fate and ecotoxicological risk of the antibiotic sulfamethoxazole across the Katari catchment (Bolivian Altiplano): application of the GREAT-ER model. Sci Total Environ 622-623: 1046-1055. https://doi.org/10.1016/j.scitotenv.2017.12.026

Ashfaq M, Yan L, Wang Y, Chen W, Wang H, Chen X, Wu W, Huang Z, Yu C-P, Sun Q (2017) Occurrence, fate, and mass balance of different classes of pharmaceuticals and personal care products in an anaerobic-anoxic-oxic wastewater treatment plant in Xiamen, China. Water Res 123:655-667. https://doi.org/10.1016/j.watres. 2017.07.014

Assress HA, Nyoni H, Mamba BB, Msagati TAM (2020) Occurrence and risk assessment of azole antifungal drugs in water and wastewater. Ecotoxicol Environ Saf 187:109868. https://doi.org/10.1016/j. ecoenv.2019.109868

Bourinbaiar AS, Jirathitikal V (2003) Low-cost anti-HIV compounds: potential application for AIDS therapy in developing countries. Curr Pharm Des 9(18):1419-1431. https://doi.org/10.2174/ 1381612033454685

Čelić M, Gros M, Farre M, Barcelo D, Petrovic M (2019) Pharmaceuticals as chemical markers of wastewater contamination in the vulnerable area of the Ebro Delta (Spain). Sci Total Environ 652:952-963. https://doi.org/10.1016/j.scitotenv.2018.10.290

Chen H, Liu S, Xu X-R, Liu S-S, Zhou G-J, Sun K-F, Zhao J-L, Ying G$G$ (2015) Antibiotics in typical marine aquaculture farms surrounding Hailing Island, South China: occurrence, bioaccumulation and human dietary exposure. Mar Pollut Bull 90(1-2):181-187. https:// doi.org/10.1016/j.marpolbul.2014.10.053

Chen H, Wang S, Guo H, Lin H, Zhang Y, Long Z, Huang H (2019) Study of marine debris around a tourist city in East China: implication for waste management. Sci Total Environ 676:278-289. https:// doi.org/10.1016/j.scitotenv.2019.04.335

Chen X, Zhang C, Yang G, Zhang J, Liu M (2020) Detection method, distribution, and risk assessment of pharmaceuticals and personal care products in the Yellow Sea and the East China Sea. Huan
Jing Ke Xue 41(1):194-204. https://doi.org/10.13227/j.hjkx. 201907028 (in Chinese)

China Meteorological Data Service Center (2020) China Meteorological Administration. http://data.cma.cn/en Accessed 25 January 2020

Cizmas L, Sharma VK, Gray CM, McDonald TJ (2015) Pharmaceuticals and personal care products in waters: occurrence, toxicity, and risk. Environ Chem Lett 13(4):381-394. https://doi.org/10.1007/s10311015-0524-4

Ding H, Wu Y, Zhang W, Zhong J, Lou Q, Yang P, Fang Y (2017) Occurrence, distribution, and risk assessment of antibiotics in the surface water of Poyang Lake, the largest freshwater lake in China. Chemosphere 184:137-147. https://doi.org/10.1016/j.chemosphere. 2017.05.148

Du J, Zhao H, Liu S, Xie H, Wang Y, Chen J (2017) Antibiotics in the coastal water of the South Yellow Sea in China: occurrence, distribution and ecological risks. Sci Total Environ 595:521-527. https:// doi.org/10.1016/j.scitotenv.2017.03.281

Du J, Zhao H, Wang Y, Xie H, Zhu M, Chen J (2019) Presence and environmental risk assessment of selected antibiotics in coastal water adjacent to mariculture areas in the Bohai Sea. Ecotoxicol Environ Saf 177:117-123. https://doi.org/10.1016/j.ecoenv.2019. 03.075

European Commission (2014) Commission Regulation (EU) No 358/ 2014 of 9 April 2014 amending Annexes II and V to Regulation (EC) No 1223/2009 of the European Parliament and of the Council on cosmetic products. Official Journal of the European Union. OJL 107, 10.4.2014, 5-9, Brussels https://eur-lex.europa.eu/legalcontent/EN/TXT/PDF/?uri=CELEX:32014R0358\&from=EN Accessed 9 September 2020

European Commission-Joint Research Centre, Institute for Health and Consumer Protection, European Chemicals Bureau (2003) Technical Guidance Document in Support of Commission Directive 93/67/EEC on Risk Assessment for New Notified Substances and Commission Regulation (EC) No. 1488/94 on Risk Assessment for Existing Substance, Part II, first ed. European Communities, Ispra, Italy. https://echa.europa.eu/documents/10162/ 16960216/tgdpart2_2ed_en.pdf Accessed 9 September 2020

Furuhama A, Toida T, Nishikawa N, Aoki Y, Yoshioka Y, Shiraishi H (2010) Development of an ecotoxicity QSAR model for the KAshinhou Tool for Ecotoxicity (KATE) system, March 2009 version. SAR QSAR Environ Res 21(5-6):403-413. https://doi.org/10. 1080/1062936X.2010.501815

Godoy AA, Kummrow F (2017) What do we know about the ecotoxicology of pharmaceutical and personal care product mixtures? A critical review. Crit Rev Environ Sci Technol 47(16):1453-1496. https://doi.org/10.1080/10643389.2017.1370991

Guibal R, Lissalde S, Brizard Y, Guibaud G (2018) Semi-continuous pharmaceutical and human tracer monitoring by POCIS sampling at the watershed-scale in an agricultural rural headwater river. $\mathrm{J}$ Hazard Mater 360:106-114. https://doi.org/10.1016/j.jhazmat. 2018.07.106

Guruge KS, Goswami P, Tanoue R, Nomiyama K, Wijesekara RGS, Dharmaratne TS (2019) First nationwide investigation and environmental risk assessment of 72 pharmaceuticals and personal care products from Sri Lankan surface waterways. Sci Total Environ 690:683-695. https://doi.org/10.1016/j.scitotenv.2019.07.042

Hammer Ø, Harper DAT, Ryan PD (2001) PAST: paleontological statistics software package for education and data analysis. Palaeontol Electron 4 (1): 9. https://palaeo-electronica.org/2001_1/past/past. pdf Accessed 9 September 2020

Han QF, Zhao S, Zhang XR, Wang XL, Song C, Wang SG (2020) Distribution, combined pollution and risk assessment of antibiotics in typical marine aquaculture farms surrounding the Yellow Sea, North China. Environ Int 138:105551. https://doi.org/10.1016/j. envint.2020.105551 
He X, Deng M, Wang Q, Yang Y, Yang Y, Nie X (2016) Residues and health risk assessment of quinolones and sulfonamides in cultured fish from Pearl River Delta, China. Aquaculture 458:38-46. https:// doi.org/10.1016/j.aquaculture.2016.02.006

Huang M, Fang L (2019) Longyan statistical yearbook-2019. http://lytjj. longyan.gov.cn/tjnj/2019/ Accessed 9 September 2020 (in Chinese)

Huang Q (2019) 2019 Yearbook of Xiamen special economic zone, China Statistics Press, Beijing. http://202.109.255.156:8130/files pub/publish/2019/\%E5\%8E\%A6\%E9\%97\%A8\%E7\%BB\%8F\% E6\%B5\%8E\%Е7\%89\%B9\% E5\%8C\%BA\%E5\%B9\%B4\%E9\% 89\%B4-2019.htm Accessed 9 September 2020 (in Chinese)

Isidori M, Parrella A, Pistillo P, Temussi F (2009) Effects of ranitidine and its photoderivatives in the aquatic environment. Environ Int 35: 821-825. https://doi.org/10.1016/j.envint.2008.12.002

KATE (2020). https://kate2.nies.go.jp/nies/index.php Accessed 9 September 2020

Kim Y, Lee K-B, Choi K (2016) Effect of runoff discharge on the environmental levels of 13 veterinary antibiotics: a case study of Han River and Kyungahn Stream, South Korea. Mar Pollut Bull 107(1): 347-354. https://doi.org/10.1016/j.marpolbul.2016.03.011

Kupferschmidt K, Cohen J (2020) WHO launches global megatrial of the four most promising coronavirus treatments. Science (March 22). https://doi.org/10.1126/science.abb8497

Lefranc F, Yeaton P, Brotchi J, Kiss R (2006) Cimetidine, an unexpected anti-tumor agent, and its potential for the treatment of glioblastoma. Int J Oncol 28(5):1021-1030. https://doi.org/10.3892/ijo.28.5.1021

Lemly AD (1996) Evaluation of the hazard quotient method for risk assessment of selenium. Ecotoxicol Environ Saf 35(2):156-162. https://doi.org/10.1006/eesa.1996.0095

Li Y, Pan S (2019) Quanzhou statistical yearbook-2019. China Statistics Press, Beijing. http://tjj.quanzhou.gov.cn/tjzl/tjsj/ndsj/201910/ t20191018_1929235.htm Accessed 9 September 2020 (in Chinese)

Lulijwa R, Rupia EJ, Alfaro AC (2020) Antibiotic use in aquaculture, policies and regulation, health and environmental risks: a review of the top 15 major producers. Rev Aquac 12:640-663. https://doi.org/ 10.1111/raq.12344

Lützhøft H-CH, Hartmann NIB, Hansen SF, Baun A (2014) PNECPredicted No Effect Concentration: PNEC-Potential Nanomaterial Enhanced Conflicts. Sound/Visual production (digital), Kgs. Lyngby: DTU Environment. https://backend.orbit.dtu.dk/ws/ portalfiles/portal/104239266/141109_L_tzh_ft_et_al_SETAC NA_2014_Vancouver_Workshop_ERA_of_ENM.pdf Accessed 9 September 2020

Lv M, Sun Q, Hu A, Hou L, Li J, Cai X, Yu C-P (2014) Pharmaceuticals and personal care products in a mesoscale subtropical watershed and their application as sewage markers. J Hazard Mater 280:696-705. https://doi.org/10.1016/j.jhazmat.2014.08.054

McCarthy DM (1983) Ranitidine or cimetidine. Ann Intern Med 99(4): 551-553. https://doi.org/10.7326/0003-4819-99-4-551

McGettigan P, Henry D (2013) Use of non-steroidal anti-inflammatory drugs that elevate cardiovascular risk: an examination of sales and essential medicines lists in low-, middle-, and high-income countries. PLoS Med 10(2):e1001388. https://doi.org/10.1371/journal. pmed. 1001388

Ministry of Ecology and Environment of the People's Republic of China (2020) The second central inspection team of ecological and environmental protection feedbacked the inspection results to Fujian Province. http:/www.mee.gov.cn/xxgk2018/xxgk/xxgk15/202005/ t20200508 778183.html Accessed 9 September 2020 (in Chinese)

Mo WY, Chen Z, Leung HM, Leung AOW (2017) Application of veterinary antibiotics in China's aquaculture industry and their potential human health risks. Environ Sci Pollut Res 24:8978-8989. https:// doi.org/10.1007/s11356-015-5607-z

Mohtar WHMW, Maulud KNA, Muhammad NS, Sharil S, Yaseen ZM (2019) Spatial and temporal risk quotient based river assessment for water resources management. Environ Pollut 248:133-144. https:// doi.org/10.1016/j.envpol.2019.02.011

Molins-Delgado D, Díaz-Cruz MS, Barceló D (2015) Introduction: personal care products in the aquatic environment In: Díaz-Cruz M, Barceló D (eds) Personal care products in the aquatic environment, The Handbook of Environmental Chemistry 36. Springer, Cham pp 1-34. https://doi.org/10.1007/698 2014302

Nakada N, Kiri K, Shinohara H, Harada A, Kuroda K, Takizawa S, Takada H (2008) Evaluation of pharmaceuticals and personal care products as water-soluble molecular markers of sewage. Environ Sci Technol 42(17):6347-6353. https://doi.org/10.1021/es7030856

Peng X, Huang Q, Zhang K, Yu Y, Wang Z, Wang C (2012) Distribution, behavior and fate of azole antifungals during mechanical, biological, and chemical treatments in sewage treatment plants in China. Sci Total Environ 426:311-3170. https://doi.org/10.1016/j.scitotenv. 2012.03.067

Prasertkulsak S, Chiemchaisri C, Chiemchaisri W, Yamamoto K (2019) Removals of pharmaceutical compounds at different sludge particle size fractions in membrane bioreactors operated under different solid retention times. J Hazard Mater 368:124-132. https://doi.org/10. 1016/j.jhazmat.2019.01.050

Schlitzer R (2018) Ocean data view. https://odv.awi.de Accessed 9 September 2020

Sun Q, Lv M, Hu A, Yang X, Yu C-P (2014a) Seasonal variation in the occurrence and removal of pharmaceuticals and personal care products in a wastewater treatment plant in Xiamen, China. J Hazard Mater 277:69-75. https://doi.org/10.1016/j.jhazmat.2013.11.056

Sun Q, Lv M, Li M, Yu CP (2014b) Personal care products in the aquatic environment in China. In: Díaz-Cruz M, Barceló D (eds) Personal care products in the aquatic environment. The Handbook of Environmental Chemistry 36. Springer, Cham, pp 73-94 https:// doi.org/10.1007/698_2014_284

Sun Q, Li Y, Li M, Ashfaq M, Lv M, Wang H, Hu A, Yu C-P (2016) PPCPs in Jiulong River estuary (China): spatiotemporal distributions, fate, and their use as chemical markers of wastewater. Chemosphere 150:590-604. https://doi.org/10.1016/j. chemosphere.2016.02.036

Tang JP, Wang S, Tai YP, Tam NF, Su LH, Shi YM, Luo BK, Tao R, Yang Y, Zhang XM (2020) Evaluation of factors influencing annual occurrence, bioaccumulation, and biomagnification of antibiotics in planktonic food webs of a large subtropical river in South China. Water Res 170:115302. https://doi.org/10.1016/j.watres.2019. 115302

United States Food \& Drug Administration (2019) Safety and effectiveness of consumer antiseptic rubs; topical antimicrobial drug products for over-the-counter human use, Federal Register, 84 FR 14847: 14847-14864. https://www.federalregister.gov/documents/ 2019/04/12/2019-06791/safety-and-effectiveness-of-consumerantiseptic-rubs-topical-antimicrobial-drug-products-for Accessed 9 September 2020

United States Food \& Drug Administration (2020) FDA requests removal of all ranitidine products (Zantac) from the market. https://www.fda. gov/news-events/press-announcements/fda-requests-removal-allranitidine-products-zantac-market Accessed 7 September 2020

Walker MJA (2011) The major impacts of James Black's drug discoveries on medicine and pharmacology. Trends Pharmacol Sci 32(4): 183-188. https://doi.org/10.1016/j.tips.2011.02.001

Wang YQ, Liu Y, Lu SY, Liu XH, Meng Y, Zhang GD, Zhang YR, Wang WL, Guo XC (2019) Occurrence and ecological risk of pharmaceutical and personal care products in surface water of the Dongting Lake, China-during rainstorm period. Environ Sci Pollut Res 26(SI; 28):28796-28807. https://doi.org/10.1007/s11356-01906047-4

Xu W, Yan W, Li X, Zou Y, Chen X, Huang W, Miao L, Zhang R, Zhang G, Zou S (2013) Antibiotics in riverine runoff of the Pearl River Delta and Pearl River Estuary, China: concentrations, mass loading 
and ecological risks. Environ Pollut 182:402-407. https://doi.org/ 10.1016/j.envpol.2013.08.004

Zhang PW, Zhou HD, Li K, Zhao XH, Liu QN, Li DJ, Zhao GF (2018) Occurrence of pharmaceuticals and personal care products, and their associated environmental risks in a large shallow lake in north China. Environ Geochem Health 40(4):1525-1539. https://doi.org/ 10.1007/s10653-018-0069-0

Zhang Y, Duan L, Wang B, Du Y, Cagnetta G, Huang J, Blaney L, Yu G (2019) Wastewater-based epidemiology in Beijing, China: prevalence of antibiotic use in flu season and association of pharmaceuticals and personal care products with socioeconomic characteristics. Environ Int 125:152-160. https://doi.org/10.1016/j.envint.2019.01. 061
Zhang Y, Duan L, Wang B, Liu CS, Jia Y, Zhai N, Blaney L, Yu G (2020) Efficient multiresidue determination method for 168 pharmaceuticals and metabolites: optimization and application to raw wastewater, wastewater effluent, and surface water in Beijing, China. Environ Pollut 261:114113. https://doi.org/10.1016/j. envpol.2020.114113

Zhangzhou Bureau of Statistics (2019) Zhangzhou statistical yearbook2019. http:/ttj..zhangzhou.gov.cn/tjnj/2019/2019.html Accessed 9 September 2020 (in Chinese)

Publisher's note Springer Nature remains neutral with regard to jurisdictional claims in published maps and institutional affiliations. 